\title{
Antiviral activities of curcumin and 6-gingerol against infection of four dengue virus serotypes in A549 human cell line in vitro
}

\author{
Jonathan Alvin Nugraha Halim ${ }^{1}$, Stefanie Natalia Halim ${ }^{1}$, Dionisius Denis ${ }^{2}$, Sotianingsih Haryanto ${ }^{3}$, Edi Dharmana ${ }^{1}$, Rebri- \\ arina Hapsari ${ }^{1}$, R. Tedjo Sasmono ${ }^{2}$, and Benediktus Yohan ${ }^{2, *}$ \\ ${ }^{1}$ Faculty of Medicine, Diponegoro University, Jl. Prof. Sudarto SH, Tembalang, Semarang 50275, Indonesia \\ ${ }^{2}$ Eijkman Institute for Molecular Biology, Ministry of Research and Technology/National Agency for Research and Innovation, Jl. Diponegoro \\ 69, Jakarta 10430, Indonesia \\ ${ }^{3}$ University of Jambi, Jl. Jambi - Muara Bulian Muaro and Siloam Hospital, J. Soekarno-Hatta, Jambi 36139, Indonesia \\ ${ }^{*}$ Corresponding author: yohan@eijkman.go.id
}

SUBMITTED 26 September 2020 REVISED 2 February 2021 ACCEPTED 4 February 2021

\begin{abstract}
Dengue virus (DENV) is the most geographically widespread arbovirus causing dengue disease epidemics in tropical and subtropical regions. Nature provides abundant plants as a source for lead molecules against various diseases including DENV infection. We investigated the antiviral effect of curcumin and 6-gingerol, the major active constituent of turmeric (Curcuma longa Linn.) and ginger (Zingiber officinale Roscoe), respectively, against all four serotypes of DENV infecting human lung epithelial carcinoma (A549) cell line in vitro. Both compounds generated cell cytotoxicity to A549 cells at CC50 values of $108 \mu \mathrm{M}$ for curcumin and $210 \mu \mathrm{M}$ for 6-gingerol. The compound curcumin showed antiviral properties as described by $\mathrm{IC}_{50}$ of $20.60,13.95,25.54$, and $12.35 \mu \mathrm{M}$, while 6-gingerol of $14.70,14.17,78.76$, and $112.84 \mu \mathrm{M}$ for DENV-1, $-2,-3$, and -4 , respectively. Different levels of antiviral properties were observed between DENV serotypes. Our findings suggest that the antiviral assay of compounds against DENV should be performed to all four serotypes and not limited to a particular serotype. In conclusion, curcumin and 6-gingerol exhibit antiviral properties against DENV infection and could provide a new therapeutic approach for dengue disease treatment strategies.
\end{abstract}

KEYWORDS 6-gingerol; A549; antivirus; curcumin; dengue virus; natural product

\section{Introduction}

Dengue virus (DENV) is considered the most geographically widespread arthropod-borne virus with an increased frequency of epidemics and severe disease manifestation in hyperendemic countries (Guzman and Harris 2015). It is estimated that 390 million cases of DENV infections occur worldwide annually (Bhatt et al. 2013; Guzman and Harris 2015). Over the past 50 years, the world has experienced a dramatic increase in dengue incidence to almost 30-folds (Guo et al. 2017), facilitated by virus transmission predominantly by Aedes aegypti and to a lesser extent Aedes albopticus mosquito vectors (Guzman et al. 2016). The four DENV serotypes (DENV-1, -2, -3, and -4) can cause a wide range of disease in human, from asymptomatic, classical fever Dengue Fever, to the lifethreatening conditions Dengue Hemorrhagic Fever and Dengue Shock Syndrome (Martina et al. 2009).

The current disease management for DENV infection is limited to early detection, fluid replacement, and symptomatic therapy, although research has proven the association of viral load with the severity of the disease in the patients (Wang et al. 2003). The first-ever dengue vaccine Dengvaxia (CYD-TDV) still has limited use in the target population below nine years old (Dighe et al. 2019) and the development of anti-DENV drugs has been in a slow process. There is no licensed antiviral therapy available to date and only four small molecule anti-DENV drugs have entered phase I and phase II clinical trials. Although these drugs meet the required safety profile, they could not reduce viral load as expected (Tian et al. 2018). With the current unavailability of antiviral therapy for DENV infection, a search for compounds having antiviral effect needs to be established. One of the possible sources of a compound with anti-DENV activities will be from natural sources.

Indonesia has been known to have an abundant source of medicinal plants. Turmeric (Curcuma longa Linn.) and ginger (Zingiber officinale Roscoe), both from the family Zingiberaceae, have been used by generations of people around the world as a dietary spice, food preservative, and traditional herbal medicine (Soleimani et al. 2018). Turmeric contains a major active constituent called curcumin (Soleimani et al. 2018), while ginger contains 6- 
gingerol (Kubra and Rao 2012; Wang et al. 2014). Researchers have shown the antioxidant, anti-inflammatory, anti-neoplastic, anti-microbial, and antiviral abilities of curcumin (Gupta et al. 2013; Kocaadam and Şanlier 2017) and 6-gingerol (Chrubasik et al. 2005). Curcumin, which is considered a non-mutagenic and non-genotoxic agent (Soleimani et al. 2018), has shown its antiviral properties against Flaviviridae viruses such as Zika Virus (Mounce et al. 2017), Hepatitis C Virus (HCV) (Anggakusuma et al. 2014), Japanese Encephalitis Virus (Dutta et al. 2009), and DENV-2 (Padilla-S et al. 2014). Fresh ginger has shown its inhibitory effect against human respiratory syncytial virus (HRSV) (Chang et al. 2013) and HCV (El-adawi et al. 2011).

Human alveolar epithelial A549 cells have been proven suitable for use as a DENV infection model in vitro (Yohan et al. 2014). The use of A549 cell line in DENV research was based on the evidence of viral antigen detection in macrophages and vascular endothelial cells of the lung (Jessie et al. 2004). The antiviral effect of curcumin and 6-gingerol to DENV has been reported although limited to a particular serotype (PadillaS et al. 2014; Sharma et al. 2015). The differing genetic of DENV serotypes may cause differences in their virulence (Holmes and Burch 2000). Hence, an antiviral study against all four DENV serotypes in human cells will give more insights into dengue pathogenesis. In this study, we investigated the antiviral effect of curcumin and 6-gingerol on the growth of all four DENV serotypes in human A549 cell line. Findings from this study may be beneficial for the development of anti-DENV drug therapy from natural resources as alternative therapeutic approach for dengue disease.

\section{Materials and Methods}

\subsection{DENV serotypes}

Four DENV serotypes of Indonesian isolates were used. All virus stocks were generated from a low-passage number (maximum of five passages) of the virus in Vero cells. The DENV-1 strain JMB-034 was isolated from a dengue patient in Jambi (Haryanto et al. 2016). The other serotypes DENV-2 strain SUB-011, DENV-3 strain SUB006, and DENV-4 strain SUB-007 were isolated from patients in Surabaya, East Java (Aryati et al. 2013; Wardhani et al. 2017). The harvested culture supernatants containing viable DENV were stored at $-80{ }^{\circ} \mathrm{C}$ until use and their titers were measured using standard plaque assay method in BHK21 cells, as described previously (Yohan et al. 2014; Sasmono et al. 2015).

\subsection{Cell cultivation and maintenance}

Cell lines were obtained from ATCC. The human (Homo sapiens) alveolar epithelial carcinoma A549 (ATCC CCL185) and Syrian golden hamster (Mesocricetus auratus) fibroblast BHK-21 (ATCC CCL-10) cells were grown and maintained in RPMI 1640 Medium (Gibco-Thermo Fisher
Scientific, CA, USA). The African green monkey (Cercopithecus aethiops) Vero (ATCC CCL-81) cells were maintained in Minimum Essential Medium (Gibco). The media were supplemented with $10 \%$ fetal bovine serum (FBS), $2 \mathrm{mM}$ of L-glutamine, $100 \mathrm{U} / \mathrm{mL}$ of penicillin, and 100 $\mu \mathrm{g} / \mathrm{mL}$ of streptomycin (all from Gibco). Cells were maintained in a humidified $37^{\circ} \mathrm{C}$ incubator with $5 \% \mathrm{CO}_{2}$ supplementation (Yohan et al. 2014).

\subsection{A549 cell viability test}

Curcumin ( $\geq 65 \%$, HPLC) and 6-gingerol ( $\geq 98 \%$, HPLC) were purchased from Sigma-Aldrich in powder and lyophilized forms, respectively. Both compounds were solubilized using dimethyl sulfoxide (DMSO) (SigmaAldrich, USA) as a vehicle into stock solutions of known molarity. The stock solutions were then diluted into working solutions using RPMI medium supplemented with $10 \%$ FBS. The cytotoxicity of the compounds was tested in A549 cells, seeded $1 \times 10^{5}$ cells/well of 96-well plate and grown overnight at $37^{\circ} \mathrm{C}, 5 \% \mathrm{CO}_{2}$. Serially diluted compounds were added into the cells monolayer in triplicate and tested with 3-(4,5-dimethylthiazol-2-yl)-2,5-diphenyl tetrazolium bromide (MTT) using the MTT Cell Proliferation Assay Kit (Trevigen, Gaithersburg, MD, USA) after $48 \mathrm{~h}$ of incubation at $37{ }^{\circ} \mathrm{C}, 5 \% \mathrm{CO}_{2}$, according to the protocol described by the manufacturer. Following the formation of formazan complexes, the plate was read at $570 \mathrm{~nm}$ using a microplate reader. The percentage of cell viability was measured as a comparison to the mediumonly controls. A dose-response curve was obtained using non-linear regression (curve fit) and the cytotoxic concentration was calculated as median cell cytotoxicity $\left(\mathrm{CC}_{50}\right)$ in which the concentration of compound that reduced the cell's viability by half.

\subsection{DENV antiviral activity testing}

The A549 cells were seeded at $1 \times 10^{5}$ cells/well in 96-well plate and subjected to infection with DENV-1, DENV-2, DENV-3, or DENV-4 with multiplicity of infection (MOI) value of 1 , described hypothetically as one virus particle per cell. Compounds treatment was done using 10, 25, and $50 \mu \mathrm{M}$ of curcumin and 50,100, and $200 \mu \mathrm{M}$ of 6gingerol, selected as sub-cytotoxic concentrations following the $\mathrm{CC}_{50}$ values determined from A549 cell viability test. Treatment of cells with calculated concentrations of compounds was done using co-treatment method, where the mixture of DENV and compounds was added to cell monolayer and allowed to react at $37^{\circ} \mathrm{C}, 5 \% \mathrm{CO}_{2}$ for $48 \mathrm{~h}$, without removal of inoculant or wash steps, as described previously (Chen et al. 2013). Following the incubation period, the supernatant was transferred into microtubes for the virus titration using plaque assay in BHK21 cells. The calculated virus titer was normalized to the medium only control (without compound or $0 \mu \mathrm{M}$ ) and presented as a percent of inhibition. The median inhibitory concentration ( $\mathrm{IC}_{50}$ ) was measured as the concentration of compound that can inhibit $50 \%$ of virus titer. A vehicle control is used to monitor the effect of DMSO diluent in the system. 


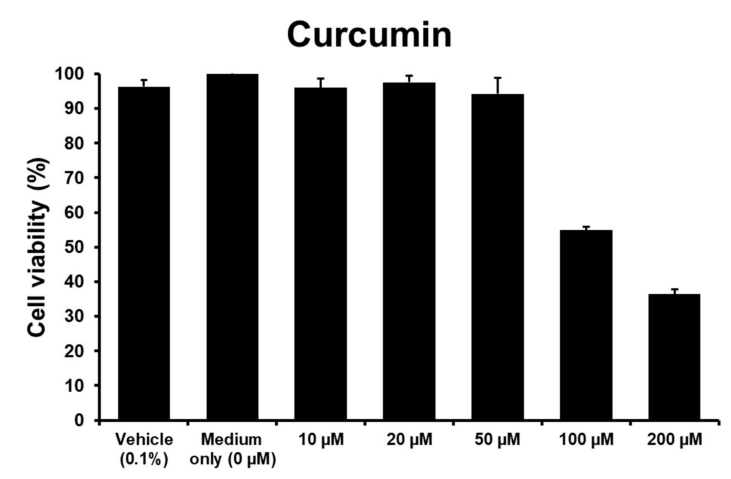

(a)

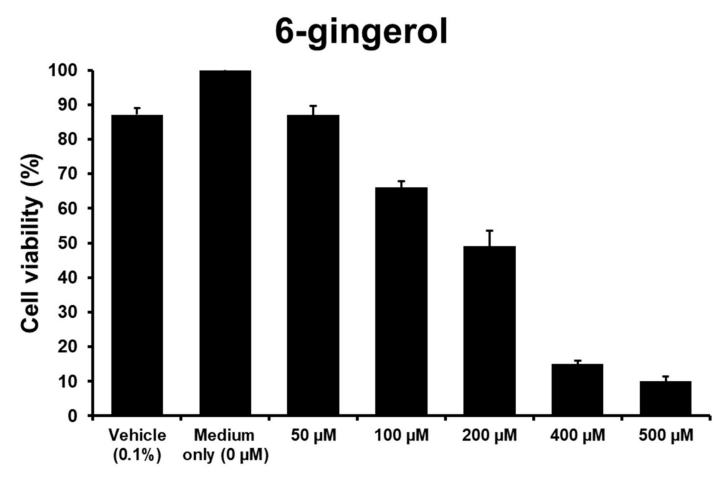

(b)

FIGURE 1 . Cell cytotoxicity of different concentrations of curcumin (a) and 6-gingerol (b) to A549 cells, as determined by CC ${ }_{50}$. Both compounds showed significant dose-dependent cell cytotoxicity. Treatment of cells with $0.1 \%$ of DMSO was used as vehicle control.

The vehicle control was prepared as $0.1 \% \mathrm{v} / \mathrm{v}$ of DMSO, a concentration that was higher than the highest concentration of compounds in the testing.

\subsection{Statistical analysis, $C C_{50}$ and $I C_{50}$ calculations}

Statistical analyses were conducted using SPSS Statistics software version 17.0 (SPSS Inc., USA). Mean and standard error of mean (SEM) from three independent experiments were calculated. The comparison between groups in experimental results was analyzed using oneway ANOVA, followed by Tukey's post hoc test. A pvalue less than 0.05 was considered as statistically significant. The $\mathrm{CC}_{50}$ and $\mathrm{IC}_{50}$ values were calculated using AAT Bioquest Quest Graph $\mathrm{IC}_{50}$ calculator (available online at https://www.aatbio.com/tools/ic50-calculator) based on the four-parameters logistic equation to generate a sigmoid function.

\section{Results and Discussion}

\subsection{Cytotoxicity of curcumin and 6-Gingerol to A549 cells}

The cells' cytotoxicity properties of curcumin and 6gingerol were measured using standard MTT assay for measurement of cells' viability. Both curcumin and 6gingerol reduced the viability of A549 cells in a dose dependent manner. The median cell cytotoxicity $\mathrm{CC}_{50}$ of curcumin and 6-gingerol were measured at $108 \mu \mathrm{M}$ and $210 \mu \mathrm{M}$, respectively (Figure 1). Both curcumin and 6-

TABLE 1 The antiviral activities of curcumin and 6-gingerol against four DENV serotypes as determined by median inhibitory concentration $\left(\mathrm{IC}_{50}\right)$.

\begin{tabular}{lllll}
\hline \multirow{2}{*}{ Compound } & \multicolumn{4}{l}{$\mathrm{IC}$ 50 of compound to DENV challenge $(\mu \mathrm{M})$} \\
\cline { 2 - 5 } & $\mathrm{DENV}-1$ & $\mathrm{DENV}-2$ & $\mathrm{DENV}-3$ & $\mathrm{DENV}-4$ \\
\hline Curcumin & 20.60 & 13.95 & 25.54 & 12.35 \\
6-gingerol & 14.70 & 14.17 & 78.76 & 112.84 \\
\hline
\end{tabular}

gingerol significantly reduced the A549 cell viability in a dose-dependent manner $\left(\mathrm{R}^{2}=0.9132, p=0.0029\right.$ and $\mathrm{R}^{2}=$ $0.9149, p=0.0001$, for curcumin and 6-gingerol, respectively).

\subsection{Antiviral activities of curcumin and 6-gingerol against DENV}

Following the $\mathrm{CC}_{50}$ data, the antiviral testing of curcumin and 6-gingerol was set at sub-cytotoxic concentrations. Curcumin and 6-gingerol significantly inhibited the growth of all DENV serotypes (Figure 2 and 3, respectively). For curcumin, all concentrations tested significantly inhibited the growth of all DENV serotypes compared to the medium-only group $(p<0.05)$, except in two experimental conditions at $10 \mu \mathrm{M}$ and $25 \mu \mathrm{M}$ in DENV-3 (Figure 2). On the other hand, for 6-gingerol, all concentrations tested show a significant reduction in the growth of all DENV serotypes $(p<0.05)$ except at $50 \mu \mathrm{M}$ in DENV-3 (Figure 3).

The inhibition profiles were increased along with the increasing concentration of compounds compared to the medium only control. Vehicle control resulted in not significant reduction of virus titers compared to control (data not shown). We observed a variable median inhibitory concentration $\mathrm{IC}_{50}$ results for each DENV serotype (Table 1).

The compound curcumin has $\mathrm{IC}_{50}$ of 20.60, 13.95, 25.54, and $12.35 \mu \mathrm{M}$ against DENV-1, -2, -3, and -4, respectively (Table 1). Curcumin showed the highest antiviral activities to DENV-4 compared to other DENV serotypes. Nevertheless, $\mathrm{IC}_{50}$ values for all serotypes were quite similar. For 6-gingerol, the compound was inhibiting the growth of DENV with IC $_{50}$ values of 14.70, 14.17, 78.76, and $112.84 \mu \mathrm{M}$ for DENV-1, -2 , -3 , and -4 , respectively (Table 1$)$. While highest antiviral activity was observed for DENV-2, the compound 6-gingerol showed higher antiviral potency for DENV-1 and DENV-2 compared to DENV-3 and DENV-4. 
Curcumin
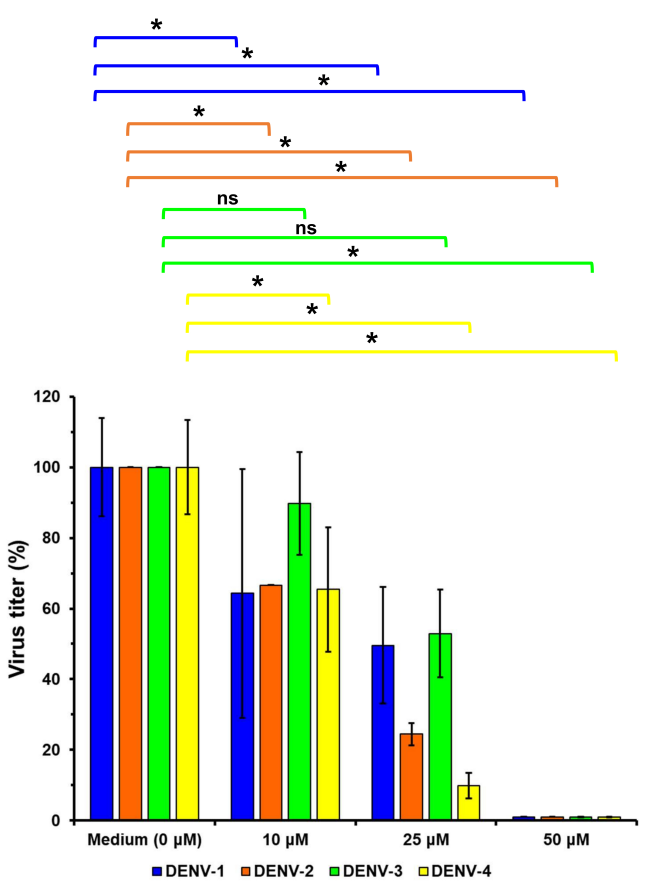

FIGURE 2 Antiviral activity profiles of curcumin against all four DENV serotypes, measured as percentage of viable virus titer in treatment groups to the medium only control after $48 \mathrm{~h}$ of assay in A549 cells. ns, not significant; ${ }^{*}, p<0.05$.

\subsection{Discussion}

The significant increase in dengue research during the past decades covers topics on dengue virology, pathogenesis, and immunology and progress in developing antivirals, vaccines, and new vector-control strategies that are important for dengue control and prevention (Guzman and Harris 2015). We tested the antiviral properties of curcumin and 6-gingerol against all four serotypes of wild strain DENV on A549 cell lines. The A549 cell line was used for its susceptibility to DENV infection and showed superior suitability compared to other human cell lines (Yohan et al. 2014).

As an active compound from nature, curcumin and 6gingerol can also be toxic and induce apoptosis to cells (Kaushik et al. 2012; Impheng et al. 2015). We found that curcumin has cytotoxic property although it did not significantly affect A549 cells' viability in concentrations up to $50 \mu \mathrm{M}$ with $\mathrm{CC}_{50}$ of $108 \mu \mathrm{M}$ after $48 \mathrm{~h}$ of cell treatment (Figure 1a), a result that is comparable to a previous study by Kaushik et al. (2012). In the other hand, 6-gingerol showed cytotoxicity to A549 cells with $\mathrm{CC}_{50}$ of $210 \mu \mathrm{M}$ (Figure 1b), comparable to other result observed elsewhere (Kim et al. 2008).

Antiviral activities of curcumin against DENV-2 has been reported (Padilla-S et al. 2014; Balasubramanian et al. 2019). The activity against DENV or enveloped virus is believed through the inhibition of Ubiquitin Proteasome System (UPS) (Chen et al. 2013; Padilla-S et al.

\section{6-gingerol}
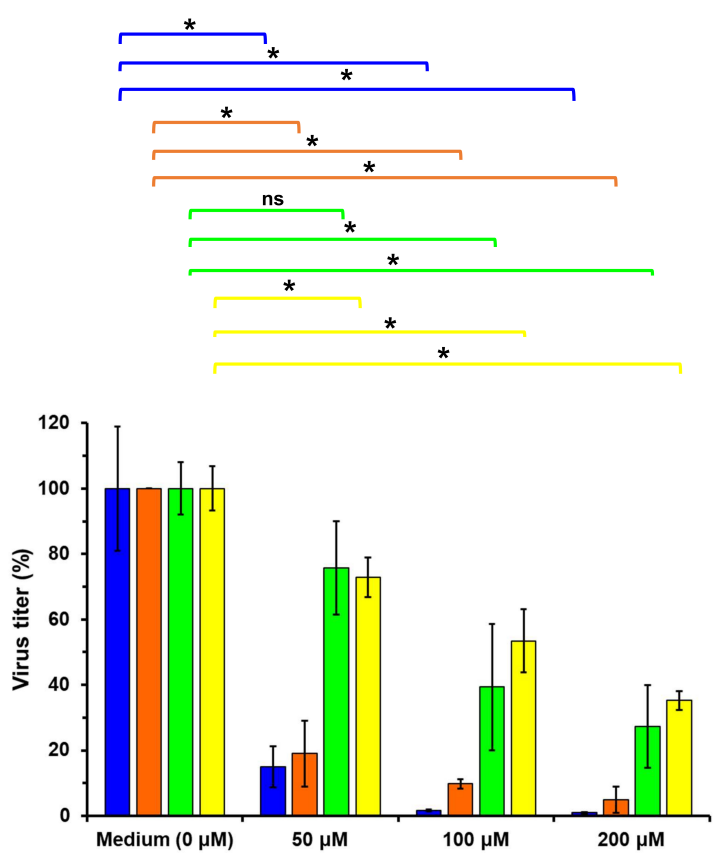

FIGURE 3 Antiviral activity profiles of 6 -gingerol against all four DENV serotypes, measured as percentage of viable virus titer in treatment groups to the medium only control after $48 \mathrm{~h}$ of assay in A549 cells. ns, not significant; ${ }^{*}, p<0.05$.

2014) which plays a role in viral replication (Glickman and Ciechanover 2002). In this study, we found that curcumin could inhibit all four DENV serotypes in the same manner (Figure 2), although different levels of $\mathrm{IC}_{50}$ was observed for each serotype (Table 1). Our result suggested similar antiviral potency of curcumin to all DENV serotypes. The effect of curcumin to DENV-2 was in accordance with previous result by Padilla-S et al. (2014). To the best of our knowledge, this is the first study to explore the antiviral ability of curcumin against all four serotypes of wild-type DENVs. The possible mechanisms of curcumin's antiviral properties include membrane-disturbing properties (Chen et al. 2013), altering membrane fluidity (Anggakusuma et al. 2014), and inhibiting cell binding (Mounce et al. 2017).

The compound 6-gingerol is known to exhibit a variety of biological activities including anticancer, antiinflammation, and antioxidant (Wang et al. 2014). In this study, 6-gingerol, also revealed anti-DENV properties shown by the reduction of viral growth along with the increasing 6-gingerol concentration in the in vitro system (Figure 3). Previous study demonstrated the ability of fresh lipophilic juice of ginger to cause complete inhibition of HCV replication, a member of Flavivirus family like DENV (El-adawi et al. 2011). Fresh ginger is effective against HRSV-induced plaque formation on HepG2 and A549 cell lines by blocking viral attachment and internalization by interfering $\mathrm{G}$ protein and $\mathrm{F}$ protein (Chang et al. 
2013). The administration of 6-gingerol was manifested as inhibition of fatty acid synthase (FASN) expression (Impheng et al. 2015), which is a biosynthetic pathway to establish DENV replication complexes (Heaton et al. 2010). The aqueous extract of ginger rhizome inhibited the activity of matrix metalloproteinase (MMP)-2 and MMP-9, while upregulating the expression of tissue inhibitor metalloproteinase (TIMP)-1 and TIMP-2 in DENV infected cells (Sharma et al. 2015). Interestingly, the antiviral activity of 6-gingerol was found to be higher in DENV-1 and -2 compared to DENV-3 and -4. The fact that 6-gingerol has different antiviral properties to four DENV serotypes is of merit for further confirmatory exploration whether different genetic of DENV serotypes attributed to these findings.

Our results add information on the antiviral properties of curcumin and 6-gingerol against all four serotypes of DENV. In addition, we promote that antiviral assay of compounds against DENV should be performed to all four serotypes and not limited to a particular serotype. Nevertheless, our study has limitations. The study design was aimed only to inspect the antiviral properties of curcumin and 6-gingerol in four DENV serotypes. The biological pathway mechanisms underlying the virus inhibition effect were not sought. More in-depth studies are needed to confirm our findings. In addition, the availability of different compound sources with different purities in the market may also give impact on the results generated. To the best of our knowledge, this is the first study describing the antiviral effects of curcumin and 6-gingerol to all four DENV serotypes.

\section{Conclusions}

In conclusion, curcumin, the major active compound of turmeric and 6-gingerol, the major active constituents of ginger, have shown antiviral activities against all four serotypes of DENV. Curcumin and 6-gingerol may have potentials in the development of anti-DENV drug therapy from natural resources and could provide an alternative therapeutic approach for dengue disease treatment strategies.

\section{Acknowledgments}

This study was carried out within the framework of undergraduate research program between Eijkman Institute for Molecular Biology and Faculty of Medicine, Diponegoro University. Financial support for the study was given by the Ministry of Research and Technology, Republic of Indonesia to RTS.

\section{Authors' contributions}

RTS, SH, ED, RH, BY designed the study. ED, RH, $\mathrm{SH}$, RTS performed study supervision. JANH, SNH, DD, BY carried out the laboratory work. JANH, SNH, DD,
BY analyzed the data. JANH, DD, BY, RTS wrote the manuscript. All authors read and approved the final version of the manuscript.

\section{Competing interests}

RTS serves as member of IJBiotech's editorial board. Other authors declare that they do not have competing interests.

\section{References}

Anggakusuma, Colpitts CC, Schang LM, Rachmawati H, Frentzen A, Pfaender S, Behrendt P, Brown RJ, Bankwitz D, Steinmann J, Ott M, Meuleman P, Rice CM, Ploss A, Pietschmann T, Steinmann E. 2014. Turmeric curcumin inhibits entry of all hepatitis $\mathrm{C}$ virus genotypes into human liver cells. Gut. 63(7):1137-1149. doi:10.1136/gutjnl-2012-304299.

Aryati A, Trimarsanto H, Yohan B, Wardhani P, Fahri S, Sasmono RT. 2013. Performance of commercial dengue NS1 ELISA and molecular analysis of NS1 gene of dengue viruses obtained during surveillance in Indonesia. BMC Infect Dis. 13(1). doi:10.1186/1471-2334-13-611.

Balasubramanian A, Pilankatta R, Teramoto T, Sajith AM, Nwulia E, Kulkarni A, Padmanabhan R. 2019. Inhibition of dengue virus by curcuminoids. Antiviral Res. 162:71-78. doi:10.1016/j.antiviral.2018.12.002.

Bhatt S, Gething PW, Brady OJ, Messina JP, Farlow AW, Moyes CL, Drake JM, Brownstein JS, Hoen AG, Sankoh O, et al. 2013. The global distribution and burden of dengue. Nature. 496(7446):504-507. doi:10.1038/nature12060.

Chang JS, Wang KC, Yeh CF, Shieh DE, Chiang LC. 2013. Fresh ginger (Zingiber officinale) has anti-viral activity against human respiratory syncytial virus in human respiratory tract cell lines. J Ethnopharmacol. 145(1):146-151. doi:10.1016/j.jep.2012.10.043.

Chen TY, Chen DY, Wen HW, Ou JL, Chiou SS, Chen JM, Wong ML, Hsu WL. 2013. Inhibition of Enveloped Viruses Infectivity by Curcumin. PLoS ONE. 8(5). doi:10.1371/journal.pone.0062482.

Chrubasik S, Pittler MH, Roufogalis BD. 2005. Zingiberis rhizoma: A comprehensive review on the ginger effect and efficacy profiles. Phytomedicine. 12(9):684701. doi:10.1016/j.phymed.2004.07.009.

Dighe SN, Ekwudu O, Dua K, Chellappan DK, Katavic PL, Collet TA. 2019. Recent update on anti-dengue drug discovery. Eur J Med Chem. 176:431-455. doi:10.1016/j.ejmech.2019.05.010.

Dutta K, Ghosh D, Basu A. 2009. Curcumin protects neuronal cells from japanese encephalitis virus-mediated cell death and also inhibits infective viral particle formation by dysregulation of ubiquitin-proteasome system. J Neuroimmune Pharmacol. 4(3):328-337. doi:10.1007/s11481-009-9158-2. 
El-adawi H, El-demellawy M, El-wahab AA. 2011. Some Medicinal Plant Extracts Exhibit Potency 2. Materials and Methods. J Biosci Tech. 2(1):223-231.

Glickman MH, Ciechanover A. 2002. The ubiquitinproteasome proteolytic pathway: Destruction for the sake of construction. Physiol Rev. 82(2):373-428. doi:10.1152/physrev.00027.2001.

Guo C, Zhou Z, Wen Z, Liu Y, Zeng C, Xiao D, Ou M, Han Y, Huang S, Liu D, Ye X, Zou X, Wu J, Wang H, Zeng EY, Jing C, Yang G. 2017. Global epidemiology of dengue outbreaks in 1990-2015: A systematic review and meta-analysis. Front Cell Infect Microbiol. 7. doi:10.3389/fcimb.2017.00317.

Gupta SC, Sung B, Kim JH, Prasad S, Li S, Aggarwal BB. 2013. Multitargeting by turmeric, the golden spice: From kitchen to clinic. Mol Nutr Food Res. 57(9):1510-1528. doi:10.1002/mnfr.201100741.

Guzman MG, Gubler DJ, Izquierdo A, Martinez E, Halstead SB. 2016. Dengue infection. Nat Rev Dis Primers. 2. doi:10.1038/nrdp.2016.55.

Guzman MG, Harris E. 2015. Dengue. Lancet. 385(9966):453-465. doi:10.1016/S01406736(14)60572-9.

Haryanto S, Hayati RF, Yohan B, Sijabat L, Sihite IF, Fahri S, Meutiawati F, Halim JA, Halim SN, Soebandrio A, Sasmono RT. 2016. The molecular and clinical features of dengue during outbreak in Jambi, Indonesia in 2015. Pathog Global Health. 110(3):119-129. doi:10.1080/20477724.2016.1184864.

Heaton NS, Perera R, Berger KL, Khadka S, LaCount DJ, Kuhn RJ, Randall G. 2010. Dengue virus nonstructural protein 3 redistributes fatty acid synthase to sites of viral replication and increases cellular fatty acid synthesis. Proc Natl Acad Sci USA. 107(40):1734517350. doi:10.1073/pnas.1010811107.

Holmes EC, Burch SS. 2000. The causes and consequences of genetic variation in dengue virus. Trends Microbiol. 8(2):74-77. doi:10.1016/S0966842X(99)01669-8.

Impheng $\mathrm{H}$, Richert L, Pekthong D, Scholfield CN, Pongcharoen S, Pungpetchara I, Srisawang P. 2015. [6]-gingerol inhibits de novo fatty acid synthesis and carnitine palmitoyltransferase- 1 activity which triggers apoptosis in HepG2. Am J Cancer Res. 5(4):1319-1336.

Jessie K, Fong MY, Devi S, Lam SK, Wong KT. 2004. Localization of dengue virus in naturally infected human tissues, by immunohistochemistry and in situ hybridization. J Infect Dis. 189(8):1411-1418. doi:10.1086/383043.

Kaushik G, Kaushik T, Yadav SK, Sharma SK, Ranawat P, Khanduja KL, Pathak CM. 2012. Curcumin sensitizes lung adenocarcinoma cells to apoptosis via intracellular redox status mediated pathway. Indian J Exp Biol. 50(12):853-861.

Kim JS, Lee SI, Park HW, Yang JH, Shin TY, Kim YC, Baek NI, Kim SH, Choi SU, Kwon BM, Leem KH, Jung MY, Kim DK. 2008. Cytotoxic com- ponents from the dried rhizomes of Zingiber officinale Roscoe. Arch Pharmacal Res. 31(4):415-418. doi:10.1007/s12272-001-1172-y.

Kocaadam B, Şanlier N. 2017. Curcumin, an active component of turmeric (Curcuma longa), and its effects on health. Crit Rev Food Sci Nutr. 57(13):2889-2895. doi:10.1080/10408398.2015.1077195.

Kubra IR, Rao LJM. 2012. An Impression on Current Developments in the Technology, Chemistry, and Biological Activities of Ginger (Zingiber officinale Roscoe). Crit Rev Food Sci Nutr. 52(8):651-688. doi:10.1080/10408398.2010.505689.

Martina BE, Koraka P, Osterhaus AD. 2009. Dengue virus pathogenesis: An integrated view. Clin Microbiol Rev. 22(4):564-581. doi:10.1128/CMR.00035-09.

Mounce BC, Cesaro T, Carrau L, Vallet T, Vignuzzi M. 2017. Curcumin inhibits Zika and chikungunya virus infection by inhibiting cell binding. Antiviral Res. 142:148-157. doi:10.1016/j.antiviral.2017.03.014.

Padilla-S L, Rodríguez A, Gonzales MM, Gallego-G JC, Castaño-O JC. 2014. Inhibitory effects of curcumin on dengue virus type 2-infected cells in vitro. Arch Virol. 159(3):573-579. doi:10.1007/s00705-013-18496.

Sasmono RT, Wahid I, Trimarsanto H, Yohan B, Wahyuni S, Hertanto M, Yusuf I, Mubin H, Ganda IJ, Latief R, Bifani PJ, Shi PY, Schreiber MJ. 2015. Genomic analysis and growth characteristic of dengue viruses from Makassar, Indonesia. Infect Genet Evol 32:165177. doi:10.1016/j.meegid.2015.03.006.

Sharma BK, Klinzing DC, Ramos JD. 2015. Zingiber officinale roscoe aqueous extract modulates matrixmetalloproteinases and tissue inhibitors of metalloproteinases expressions in dengue virus-infected cells: Implications for prevention of vascular permeability. Trop J Pharm Res. 14(8):1371-1381. doi:10.4314/tjpr.v14i8.8.

Soleimani V, Sahebkar A, Hosseinzadeh H. 2018. Turmeric (Curcuma longa) and its major constituent (curcumin) as nontoxic and safe substances: Review. Phytother Res. 32(6):985-995. doi:10.1002/ptr.6054.

Tian YS, Zhou Y, Takagi T, Kameoka M, Kawashita N. 2018. Dengue Virus and Its Inhibitors: A Brief Review. Chem Pharm Bull (Tokyo) 66(3):191-206. doi:10.1248/cpb.c17-00794.

Wang S, Zhang C, Yang G, Yang Y. 2014. Biological properties of 6-gingerol: a brief review. Nat Prod Commun 9(7):1027-1030.

Wang WK, Chao DY, Kao CL, Wu HC, Liu YC, Li CM, Lin SC, Ho ST, Huang JH, King CC. 2003. High levels of plasma dengue viral load during defervescence in patients with dengue hemorrhagic fever: implications for pathogenesis. Virology 305(2):330-338. doi:10.1006/viro.2002.1704.

Wardhani P, Aryati A, Yohan B, Trimarsanto H, Setianingsih TY, Puspitasari D, Arfijanto MV, Bramantono B, Suharto S, Sasmono RT. 2017. Clinical and virological characteristics of dengue in 
Surabaya, Indonesia. PLoS ONE 12(6):e0178443. doi:10.1371/journal.pone.0178443.

Yohan B, Kendarsari RI, Mutia K, Bowolaksono A, Harahap AR, Sasmono RT. 2014. Growth characteristics and cytokine/chemokine induction profiles of dengue viruses in various cell lines. Acta Virol 58(1):20-27. 